\title{
HEPATOLOGY
}

\section{Outcome of hepatitis $C$ virus infection in Chinese paid plasma donors: A 12-19-year cohort study}

\author{
Hui-Ying Rao, ${ }^{*, \dagger}$ De-Gui Sun, ${ }^{\ddagger}$ Rui-Feng Yang, ${ }^{*}, \dagger$ Feng Liu, ${ }^{*}, \dagger$ Jian Wang, ${ }^{*}$ Bo Feng, ${ }^{*}, \dagger$ Nan Wu, ${ }^{*}$ \\ Ji-Lian Fang, ${ }^{*}$ Guang-Jun Song, ${ }^{*}$ Hui Ma, ${ }^{*,+}$ Fang Guo, ${ }^{*, \dagger}$ Jiang-Hua Wang, ${ }^{*, \dagger}$ Xiao-Bo Li,* Qian Jin, ${ }^{*, \dagger}$ \\ Hong Qin, ${ }^{*}$ Hui Zhuang ${ }^{\S}$ and Lai Wei*,t \\ *Peking University People's Hospital, Peking University Hepatology Institute, Beijing Key Laboratory of Hepatitis C and Immunotherapy for Liver \\ Diseases, and ${ }^{\dagger}$ Peking University Health Science Center-University of Michigan Health System, Joint Institute for Translational and Clinical \\ Research, and ${ }^{\S}$ Department of Microbiology, Peking University Health Science Center, Beijing, and ${ }^{\ddagger}$ Guan County Center for Disease Control and \\ Prevention, Hebei Guan, China
}

\section{Key words}

hepatitis C virus, outcome, plasma donor.

Accepted for publication 20 July 2011

\section{Correspondence}

Professor Lai Wei, Peking University People's Hospital, Peking University Hepatology Institute, No. 11 Xizhimen South Street, Beijing 100044, China. Email:

weilai@pkuph.edu.cn

\begin{abstract}
Background and Aims: Commercial plasma donation was introduced in China in the 1970s. Cases of non-A, non-B hepatitis (hepatitis C) continued to occur, with multiple outbreaks among plasma donors in Guan county, Hebei province between 1972 and 1990. The outcomes of hepatitis C virus (HCV) infection in these paid plasma donors from six villages of Guan county were followed up for 12-19 years.

Methods: A total of 402 plasma donors with HCV infection were enrolled since antiHCV-positive in 1991 or 1998. Follow up was maintained until death or the end of the observation period. No antiviral treatment was applied during the period of infection.

Results: Follow up was lost in 23 cases. After a 12-19-year follow up, 31 donors died, with the cause of death directly related to liver disease in 15 cases, and an overall mortality of $8.18 \%(31 / 379)$. The incidence of liver cirrhosis was $10.03 \%$, and hepatocellular carcinoma (HCC) was $2.90 \%$. The rate of viral spontaneous clearing was $20.32 \%$ (77/379), and $13.69 \%$ (23/168) in males and 25.59\% (54/211) in females. In May 2010, detections were performed in 348 cases. Abnormality of liver function was related to HCV viremia. Sex and alcohol intake impacted the outcome of $\mathrm{HCV}$ infection. There was no correlation between the viral spontaneous clearance with age of infection and genotype.

Conclusions: This area has a high rate of chronicity in $\mathrm{HCV}$ infection due to plasma donation. Twenty-five years after virus infection, liver cirrhosis or HCC developed in one-tenth of patients, with an overall mortality of $8.18 \%$.
\end{abstract}

\section{Introduction}

Hepatitis C virus (HCV) infection is rated by the World Health Organization as a global health problem, based on its prevalence; the high rate of chronicity; severe complications, such as cirrhosis and hepatocellular carcinoma (HCC); as well as the high costs of antiviral therapy and liver transplantation. ${ }^{1-3}$ Screening measures by transfusion organizations, as well as preventive measures, have indeed led to a decreasing incidence of HCV infections. However, the prevalence of fully-developed illnesses and subsequent mortality caused by $\mathrm{HCV}$ are rising. ${ }^{3}$ An evaluation of the risk of progression to cirrhosis and hepatocellular carcinoma (HCC) is very important, not only for the general welfare of society, but also for the individual patient. In order determine the appropriate therapy, studies of the natural course of the disease are necessary.

Three types of studies, prospective, retrospective, and retrospective-prospective, were carried out to determine the outcomes of chronic $\mathrm{HCV}$ infection. The combined population data indicate that the disease progresses slowly over 30 years. Approximately $20 \%$ of infected individuals will progress to fibrosis and cirrhosis. Of these, $20 \%$ will progress to HCC. The possibility of progression increases with alcohol intake, male sex, and age over 40 years at infection, but appears to be independent of genotype or viral load. ${ }^{4}$

Existing studies differ widely in design, with the particular concern that specialized clinics, where some of these studies took place, are more likely to see patients with advanced chronic liver disease and less likely to see those without any symptoms. International consensus conferences have therefore called for further prospective studies, as well documented populations, indicating that natural history studies should begin with the onset of HCV infections. Of particular interest are the rare instances in which infection begins at a known time. ${ }^{5}$

Several studies have followed patient cohorts with a known onset of infection. ${ }^{5-10}$ Within the first 20 years after infection, 
hepatitis $\mathrm{C}$ follows a relatively benign course. Some variability has been shown, but overall between $5 \%$ and $25 \%$ of patients have spontaneous viral clearance, and the majority of adults have persistent viremia without clinically demonstrable liver disease. ${ }^{5-9}$ However, the natural course of $\mathrm{HCV}$ infection in plasma donors with a known onset of infection remains poorly understood, especially in China. In Austria, a 31-year follow up of 439 paid plasma donors who received hepatitis $\mathrm{C}$ infection showed that advanced liver disease developed in one-third of patients, with an overall mortality of $7 \% .^{10}$

Between 1972 and 1990, several outbreaks of hepatitis non-A, non-B virus infection linked to plasma donation occurred at plasmapheresis centers in Guan county, Hebei province. These donors were followed for 12-19 years after initial documentation of $\mathrm{HCV}$ infection. The study investigated the outcomes of HCV infection in these plasma donors from six villages of Guan country. This 12-19-year follow-up helps us to further understand the natural outcome of chronic hepatitis $\mathrm{C}$ and to clarify the long-term outcome of chronic hepatitis $\mathrm{C}$ in infected Chinese patients.

\section{Methods}

\section{Patients}

Commercial plasma donation was introduced in China in the 1970s. Prior to each donation, the donors were required to have normal alanine aminotransferase (ALT), and no HBV infection was detected. Nevertheless, cases of non-A, non-B hepatitis continued to arise, and multiple outbreaks with over 500 infected donors occurred in Guan county, Hebei province between 1972 and 1990 .

The return of blood cells is thought to be through common transfusion lines contaminated with HCV. The cause of these outbreaks was believed to be related to return of red cells to donors through contaminated transfusion lines.

After hepatitis $\mathrm{C}$ testing became available, donors from five villages were tested for hepatitis C antibody (anti-HCV) in 1991, and donors from the sixth village were tested for anti-HCV in 1998. Of the 769 registered, paid donors, 704 came back for anti-HCV testing, and $402(57.1 \%)$ of these tested positive. Because the donors were required to have normal ALT levels before donation, the date of the first test showing an increase in ALT levels was considered as the time of infection. For the donors with normal ALT levels, the lattermost plasma donation time was considered as the time of infection. Donors who tested positive for anti-HCV were invited to return for follow-up assessment every 5-6 years, between 1991 and 2008, and once a year thereafter. At each visit, the donors were evaluated, and blood was tested for anti-HCV and ALT. HCV-RNA was tested during follow-up visits in 2002, 2009, and 2010. Follow up was maintained until death or the end of the observation period (May 2010). Follow up was lost for 23 donors because of change of residence and/or telephone number. No antiviral treatment was applied during the period of infection. Twelve to 19 years later, in May 2010, anti-HCV, HCVRNA, biochemistry, and ultrasonography were detected in 348 donors of this cohort; liver stiffness measures were performed in 183 donors.

This study was approved by the Ethical Committee of Human Experimentation at Peking University People's Hospital (Beijing,
China), and was in accordance with the 1975 Declaration of Helsinki. The plasma donors were enrolled after giving their written, informed consent for the follow-up study.

\section{Biochemical tests}

Three milliliters of peripheral vein blood was collected for the biochemical detection. ALT, aspartate aminotransferase (AST), $\gamma$-glutamyltransferase $(\gamma$-GT), alkaline phosphatase, total bilirubin, direct bilirubin, total protein, and albumin were tested by an automated biochemical analyzer (7600; HITACHI, Tokyo, Japan).

\section{Virology tests}

Tests for anti-HCV were carried out using enzyme immunoassay (Chiron, Emeryville, CA, USA) between 1991 and 2005, and a chemiluminescent microparticle immunoassay (Architect; Abbott Laboratories, Chicago, IL, USA) after 2005. HCV-RNA was quantitated with Cobas Ampliprep/Cobas Taqman HCV assay (Roche Molecular Diagnostics, Branchburg, NJ, USA) that has a lower limit of detection of $15 \mathrm{IU} / \mathrm{mL}$. HCV was genotyped with a restriction fragment length polymorphism. ${ }^{11}$ Hepatitis B virus surface antigen (HBsAg) was detected by enzyme immunoassay (Abbott Laboratories, USA), and anti-HIV by enzyme immunoassay (BioMérieux, Boxtel, the Netherlands).

\section{Risk factors for HCV chronicity}

All data of risk factors for HCV chronicity were collected by using special questionnaires relating to sex, age, age at infection, symptoms, and alcohol consumption.

\section{Ultrasonography evaluation}

On the same day, the ultrasonography evaluation was carried out by two experienced gastroenterologists specifically trained in ultrasonography; the gastroenterologists were unaware of the clinical history and biochemical test results. Commerciallyavailable real-time ultrasonography equipment (Logic Book; GE Medical Systems, Milwaukee, WI, USA) was utilized. Cirrhosis was diagnosed by ultrasound, based on a quantitative scoring system derived from the appearance of the liver surface, liver parenchymal texture, intrahepatic blood vessel size, and splenic size. ${ }^{12}$

\section{Liver stiffness measured by transient elastography}

In 183 donors, non-invasive evaluation of liver fibrosis was performed using liver stiffness measurement (FibroScan [FS]; Echosens, Paris, France). The tip of the probe transducer was placed on the skin between the rib bones and the level of the right lobe of the liver. The measurement depth was between 25 and $65 \mathrm{~mm}$ below the skin surface. Ten measurements were performed, with success rates of at least $60 \%$. The results were expressed in kilopascals $(\mathrm{kPa})$. The median value was taken as the representative value. For this evaluation, fibrosis assessment was performed using a published cut-off. ${ }^{13}$ Significant fibrosis $(\mathrm{F}=2)$ was defined when the FS value was between 7.2 and $9.5 \mathrm{kPa}$, severe fibrosis $(\mathrm{F}=3)$ 
when the FS value was between 9.6 and $12.5 \mathrm{kPa}$, and cirrhosis $(\mathrm{F}=4)$ when the FS value was $>12.5 \mathrm{kPa}$. FS measurements with an interquartile range higher than $40 \%$ were excluded. Eight of the initial 183 patients were excluded because of invalid liver stiffness measurements or high interquartile range values.

\section{Diagnostic criterion}

The diagnoses of HCV infection in the present study were categorized as: (i) HCV spontaneous clearance (serum HCV-RNA undetectable); (ii) chronic HCV infection, chronic viremia (serum HCV-RNA positive); ${ }^{14}$ (iii) liver cirrhosis: ultrasonography diagnosis or clinical diagnosis in the presence of palpable liver with consistency grade III-IV and blunt margins or caput medusae, esophageal varices, ascites; and (iv) HCC: liver nodules found on ultrasound surveillance, and typical of HCC, found on computed tomography or magnetic resonance scanning scanning. ${ }^{15}$

The diagnostic criteria for fatty change in the liver by ultrasonography were as follows: ${ }^{16}$ (i) a diffuse hyperechoic echotexture (bright liver); (ii) an increased liver echotexture compared to the kidney or spleen; (iii) vascular blurring; and (iv) deep attenuation. Specifically, comparison with a non-affected parenchymal organ (kidney or spleen) is encouraged, and two additional features are sought: blurring of hepatic vessels and deep attenuation of the ultrasound signal.

\section{Statistical analysis}

Results are expressed as means \pm SE. Comparison of quantitative data was made using the Student's $t$-test. Qualitative data were analyzed using the $\chi^{2}$-test and odds ratio (OR). A $P$-value of less than 0.05 was considered to indicate a statistically-significant difference. The statistical software package used was SPSS 13.0 for Windows (SPSS, Chicago, IL, USA).

\section{Results}

\section{Relative benign outcome of $\mathrm{HCV}$ infection in Chinese paid plasma donors}

Of the 379 patients enrolled in this study in 1991 or 1998 and followed up for 12-19 years, 31 died (8.18\%, Fig. 1). Of these 31 patients, 12 were males and 19 were females, with a mean age at death of $63.2 \pm 8.3$ years. Death was directly related to liver diseases in 15 plasma donors. Five died of liver cirrhosis, and 10 died of HCC. In the 15 donors, HCV-RNA was positive, with mean viral load of $5.8 \log _{10} \mathrm{IU} / \mathrm{mL}$; 13 were $\mathrm{HCV}$ genotype $1 \mathrm{~b}$, and two were 2a. The HCV-related mortality was relatively low (3.96\%). Other causes of death were cerebral hemorrhage $(n=8)$, cerebral infarction (1), lung diseases (2), heart failure (1), myocardial infarction (1), bone cancer (1), organophosphate poisoning (1), and struck by lightning (1). Thirty eight $(10.03 \%)$ progressed to liver cirrhosis, and $11(2.90 \%)$ to HCC during the observation period.

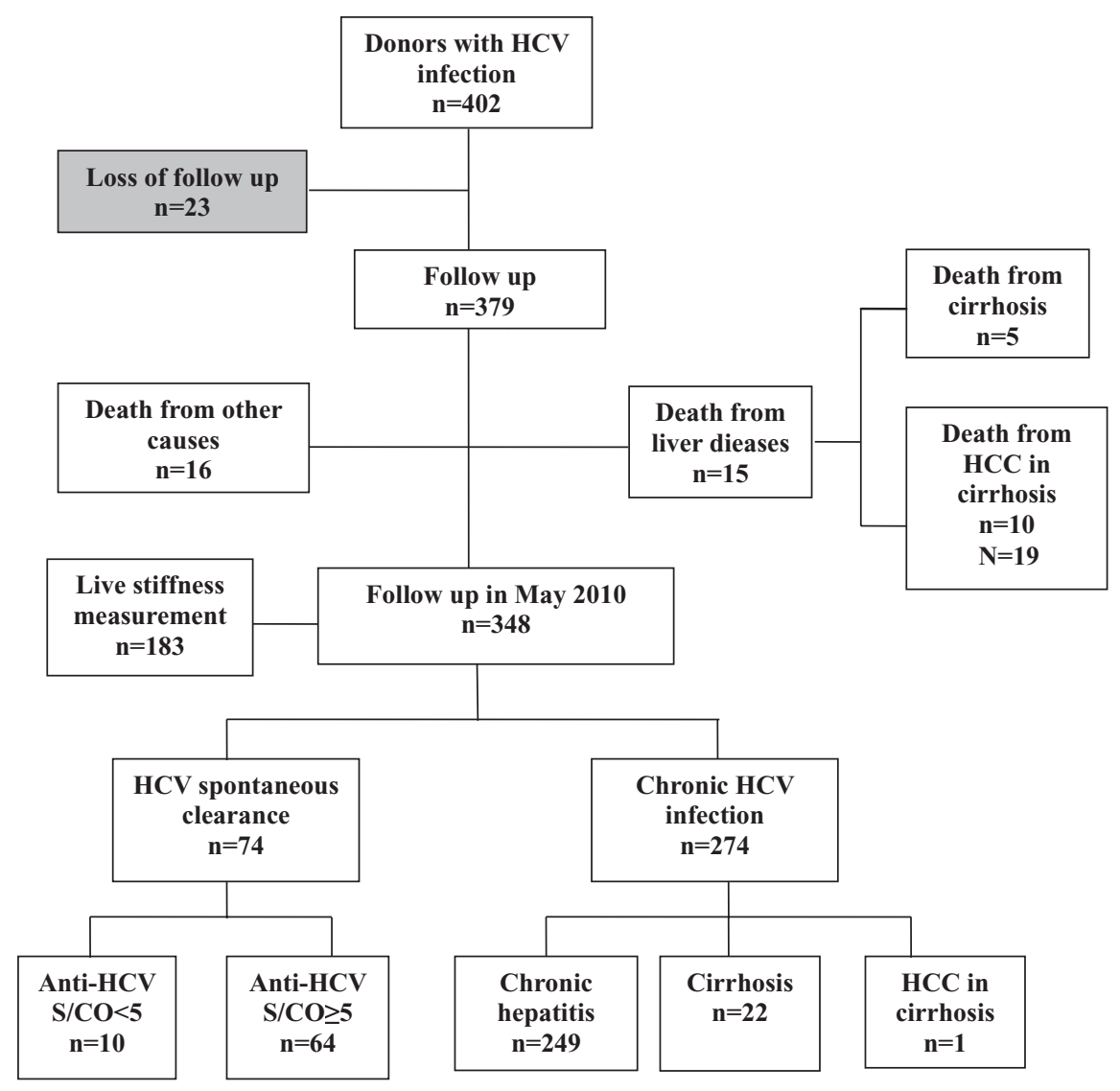

Figure 1 Summary of the outcome of the 402 donors recruited. 
Table 1 Demographic, clinical, and biological characteristics of blood donors

\begin{tabular}{lc}
\hline & $n(\%)$ or mean \pm SE \\
\hline Sex (male/female) & $156 / 192$ \\
Mean age (years) & $53.7 \pm 7.4$ \\
Mean age at infection (years) & $28.1 \pm 7.3$ \\
Mean infection duration (years) & $25.2 \pm 3.4$ \\
Alcohol consumption $>40$ g/day & $74(21.26 \%)$ \\
$\quad$ Male & $57(36.54 \%)$ \\
Female & $17(8.85 \%)$ \\
Platelet count (109/L) & $209.3 \pm 66.8$ \\
ALT (IU/L) & $45.8 \pm 42.4$ \\
AST (IU/L) & $44.8 \pm 33.1$ \\
GGT (IU/L) & $40.6 \pm 75.8$ \\
\hline
\end{tabular}

Data were expressed as $n(\%)$ or mean \pm SD. ALT, alanine aminotransferase; AST, aspartate aminotransferase; GGT, c-glutamyl transpeptidase.

The rate of chronicity in these 379 donors group was $79.68 \%$, and the rate of viral spontaneous clearance was $20.32 \%(77 / 379$, 95\% confidence interval [CI]: 16.27-24.37\%).

Of 348 plasma donors studied in May 2010, 156 were male and 192 were female, with a mean age of $53.7 \pm 7.4$ years. The characteristics of the 348 donors are shown in Table 1 . Five patients had co-infection with HBV (HBsAg positive) when re-evaluated in 2008 using the Abbott kit. All 348 donors were serum anti-HIV negative. The age at time of $\mathrm{HCV}$ infection was $28.1 \pm 7.3$ years, and the infection duration was $25.2 \pm 3.4$ years (range: $14-35$ years). Of the 348 donors, $2.87 \%$ (10/348, 95\% CI: 1.12 $4.62 \%)$ were serum anti-HCV signal-to-cutoff ratio $(\mathrm{S} / \mathrm{CO})<5$, $18.39 \%$ (64/348, 95\% CI: 14.32-22.46\%) were serum anti-HCV S/CO $\geq 5$ and HCV-RNA negative, and $78.74 \%$ (274/348, 95\% CI: $74.44-83.04 \%$ ) were anti-HCV S/CO $\geq 5$ and HCV-RNA positive. Ultrasonography evaluation showed $6.61 \%$ (95\% CI: $4.00-9.22 \%$ ) with liver cirrhosis, $0.29 \%$ (95\% CI: $-0.27 \%$ to $0.85 \%$ ) with HCC, and $19.25 \%$ (95\% CI: $15.11-23.39 \%)$ with steatohepatitis.

\section{Relation of live function abnormality to HCV viremia}

Of the 348 donors, the rate of ALT and/or AST abnormalities in the group of anti-HCV S/CO $\geq 5$ and HCV-RNA positive was $56.57 \%$ (155/274, 95\% CI: 50.70-62.44\%), anti-HCV S/CO $\geq 5$ and HCV-RNA negative was $3.13 \%$ (2/64, 95\% CI: $-1.14 \%$ to $7.40 \%)$, while that in the anti-HCV group $\mathrm{S} / \mathrm{CO}<5$ was zero. The abnormal rate of ALT and/or AST in the HCV-RNA positive group was significantly higher than that in the negative group $(57.57 \%$ vs $2.70 \%, P<0.01$; OR $=44.85,95 \%$ CI: $10.79-186.51 \%)$. The average level of ALT, AST, and $\gamma$-GT in the positive group of HCV-RNA was significantly higher than that in the negative group $(P<0.01)$ (Table 2).

\section{Impact of sex on the outcome of HCV infection}

Of the 379 donors, 145 male cases and 157 female cases were detectable for HCV-RNA. The rate of viral spontaneous clearance
Table 2 Comparison of biochemistry between patients with or without hepatitis $\mathrm{C}$ virus (HCV) spontaneous clearance

\begin{tabular}{llll}
\hline & HCV-RNA positive & HCV-RNA negative & $P$-value \\
\hline Cases $(n)$ & 274 & 74 & \\
ALT $(I U / L)$ & $53.50 \pm 44.57$ & $17.22 \pm 8.43$ & $<0.01$ \\
AST $(I U / L)$ & $50.74 \pm 34.78$ & $22.65 \pm 6.30$ & $<0.01$ \\
ALP $(I U / L)$ & $90.04 \pm 29.20$ & $85.85 \pm 25.48$ & $>0.05$ \\
$\gamma$-GT $(I U / L)$ & $45.82 \pm 83.93$ & $21.05 \pm 21.32$ & $<0.01$ \\
Tbil $(\mu \mathrm{mol} / \mathrm{L})$ & $19.15 \pm 7.68$ & $16.78 \pm 6.76$ & $>0.05$ \\
Glucose $(\mathrm{mmol} / \mathrm{L})$ & $5.26 \pm 2.07$ & $5.31 \pm 1.65$ & $>0.05$ \\
ALB $(\mathrm{G} / \mathrm{L})$ & $46.53 \pm 3.18$ & $47.64 \pm 2.44$ & $>0.05$ \\
\hline
\end{tabular}

Data were expressed as $n$ or mean \pm standard deviation. ALB, albumin; ALP, alkaline phosphatase; ALT, alanine aminotransferase; AST, aspartate aminotransferase; $\gamma$-GT, $\gamma$-glutamyltransferase; Tbil, total bilirubin.

was $13.69 \%$ in the male group and $25.59 \%$ in the female group. A significant difference was found between them $(\mathrm{OR}=2.17,95 \%$ CI: 1.27-3.71). There were 27 cases of liver cirrhosis were found: 18 male cases and nine female cases. There were also 11 cases of HCC: seven male cases and four female cases.

Of the 348 donors, the mean values of ALT and AST were significantly higher in the male donors than the female donors (Table $3, P<0.01$ ). The rate of ALT and/or AST abnormalities was significantly higher in the male donors than in the female donors (Table 3, $P<0.01$ ).

\section{Impact of alcohol intake on the outcome of HCV infection}

Seventy four of 348 cases had an alcohol intake of more than $40 \mathrm{~g}$ every day. In the HCV-RNA-negative group, there were 16 cases $(16 / 74,21.62 \%)$ of alcohol intake. In the HCV-RNA-positive group, there were 58 cases $(58 / 274,21.16 \%)$ of alcohol intake. No significant difference was found between alcohol intake and $\mathrm{HCV}$ spontaneous clearance. Of the 22 liver cirrhosis donors, 10 (45.45\%; OR $=3.92,95 \%$ CI: $1.63-9.41)$ had an alcohol intake if more than $40 \mathrm{~g}$ per day.

\section{HCV genotyping was not related to the outcome of HCV infection}

Of the 302 HCV-RNA-positive donors, $84.11 \%$ (254/302), $12.91 \%$ (39/302), and $2.98 \%$ (9/302) were HCV genotype 1 b, 2a, and $1 \mathrm{~b} / 2 \mathrm{a}$, respectively. Of the 38 liver cirrhosis donors, 32 were HCV genotype $1 b$, five were $2 a$, and one was $1 b / 2 a$. No significant difference was found between HCV genotyping and outcome of $\mathrm{HCV}$ infection $(P>0.05)$.

\section{No correlation between age at contamination and HCV spontaneous clearance rate and liver cirrhosis incidence}

We divided the 379 donors into two groups, according to the age of infection: $\leq 30$ years and $>30$ years (Table 4 ). The rate of spontaneous viral clearance in the two groups was $19.46 \%$ and $21.52 \%$. There was no significant difference between different ages at infection. The rate of liver cirrhosis incidence in the two groups 
Table 3 Comparison of hepatitis C virus (HCV)-RNA undetectable rate, alanine aminotransferase (ALT), and aspartate aminotransferase (AST) between males and females

\begin{tabular}{|c|c|c|c|c|}
\hline & Males & Females & OR & OR 95\% Cl \\
\hline Cases $(n)$ & 168 & 211 & & \\
\hline HCV-RNA negative & 23 & 54 & & \\
\hline HCV-RNA undetectable rate & $13.69 \%$ & $25.59 \% *$ & 2.17 & $1.27-3.71$ \\
\hline Cases followed in $2010(n)$ & 156 & 192 & & \\
\hline ALT & $54.88 \pm 44.13$ & $38.40 \pm 39.57^{*}$ & & \\
\hline AST & $50.03 \pm 31.97$ & $40.49 \pm 33.38^{*}$ & & \\
\hline ALT/AST normalities rate & $42.31 \%$ & $65.10 \%$ * & 2.54 & $1.65-3.93$ \\
\hline
\end{tabular}

${ }^{*} P<0.01$ versus the male group. Data were expressed as $n(\%)$ or mean \pm standard deviation. $\mathrm{Cl}$, confidence intervals; OR, odds ratio.

Table 4 Comparison of hepatitis C virus (HCV)-RNA-negative rate 14-35 years after infection among different ages

\begin{tabular}{lllllll}
\hline Age at infection & Cases & HCV-RNA positive & HCV-RNA negative & HCV-RNA-negative rate & OR & OR 95\% Cl \\
\hline All & 379 & 302 & 77 & $20.32 \%$ & $19.46 \%$ & 1 \\
$\leq 30$ & 221 & 178 & 34 & $21.52 \%$ & 1.14 & $0.69-1.88$ \\
$>30$ & 158 & 124 & 34 & & \\
\hline
\end{tabular}

$\chi^{2}=0.2420, P=0.6228 . \mathrm{Cl}$, confidence intervals; OR, odds ratio.

Table 5 Comparison of hepatitis C virus (HCV)-RNA, alanine aminotransferase (ALT), aspartate aminotransferase (AST), albumin (ALB), and platelet between different liver stiffness patients

\begin{tabular}{lllllll}
\hline FibroScan & $n$ & HCV-RNA $\log _{10} \mathrm{IU} / \mathrm{mL}$ & ALT & AST & ALB & PLT \\
\hline$<7.2 \mathrm{kPa}$ & 89 & $6.40 \pm 0.88$ & $34.3 \pm 28.9$ & $34.2 \pm 20.4$ & $46.9 \pm 2.4$ & $219.4 \pm 59.9$ \\
$7.2-9.5 \mathrm{kPa}$ & 31 & $5.89 \pm 1.50$ & $41.5 \pm 30.7$ & $38.7 \pm 21.5$ & $47.2 \pm 2.5$ & $204.9 \pm 48.9$ \\
$9.6-12.5 \mathrm{kPa}$ & 25 & $5.99 \pm 0.94$ & $52.8 \pm 39.7$ & $52.2 \pm 29.3$ & $46.7 \pm 2.7$ & $205.8 \pm 68.4$ \\
$>12.5 \mathrm{kPa}$ & 30 & $6.20 \pm 0.74$ & $81.6 \pm 63.9^{*}$ & $81.0 \pm 65.2^{*}$ & $44.4 \pm 4.0$ & $161.5 \pm 65.1^{*}$ \\
\hline
\end{tabular}

${ }^{*} P<0.01$ vs the liver stiffness $\leq 12.5 \mathrm{kPa}$ group. Data were expressed as $n(\%)$ or mean \pm SD.

was $8.14 \%$ and $12.66 \%$. There was also no significant difference between age at contamination and liver cirrhosis incidence.

\section{Multivariate analysis of factors associated with the outcome of HCV infection}

The multivariate analysis included the following variables: sex and alcohol consumption, which were found to be significant in the univariate analysis. Sex had an independent effect on spontaneous $\mathrm{HCV}$ clearance; the odds ratio for women to clear HCV infection in the multivariate model for all donors was 1.98 (95\% CI: 1.123.34) when compared to men.

\section{Liver stiffness measure}

Of the 177 donors, FS detection (Table 5) showed 89 donors with liver stiffness $<7.2 \mathrm{kPa}, 31$ donors with $7.2-9.5 \mathrm{kPa}, 25$ donors with $9.6-12.5 \mathrm{kPa}$, and 30 donors with $>12.5 \mathrm{kPa}$. The average level of ALT and AST in the liver stiffness $>12.5 \mathrm{kPa}$ group was significantly higher than that in the liver stiffness $\leq 12.5 \mathrm{kPa}$ group $(P<0.01)$. The average platelet level (PLT) in the liver stiffness $>12.5 \mathrm{kPa}$ group was significantly lower than that in the liver stiffness $\leq 12.5 \mathrm{kPa}$ group $(P<0.01)$. The donors with liver stiffness $>9.6 \mathrm{kPa}$ were all $\mathrm{HCV}$-RNA positive. No significant difference of HCV-RNA load and age at infection was found between different liver stiffness groups. In the HCV spontaneous clearance group, the liver stiffness was $5.30 \pm 1.72 \mathrm{kPa}$, and in the $\mathrm{HCV}$ chronic infection group, the liver stiffness were $11.32 \pm 9.76 \mathrm{kPa}(P<0.01$ vs the HCV spontaneous clearance group).

\section{Discussion}

The anti-HCV epidemic rate is $3.2 \%$ in the Chinese population, and it is estimated that 40 million people are infected. ${ }^{17}$ Through the screening of blood donors since 1990s, the incidence of HCV has decreased, but some patients have progressed to chronic hepatitis, liver cirrhosis, and HCC. In the past 10 years, the incidence of $\mathrm{HCV}$ infection reported by the Center for Disease Control and Prevention of China has increased evidently. ${ }^{18}$ Although there are some reports on the natural history of $\mathrm{HCV}$ infection in Western countries, ${ }^{5,7,19,20}$ few similar studies have been carried out in China, so it is necessary to observe the outcome of HCV infection in China.

In our study, all of the donors were farmers, and were not covered by social medical insurance; they needed to pay for the medical therapy themselves, and could not afford standard antivirus therapy, so these donors had not received treatment for hepatitis C. For the long-term follow up, $10.03 \%$ of patients were found to have cirrhosis, and $2.90 \%$ had HCC; the HCV-related mortality 
was $3.96 \%$. Although we found a pattern of more progressive disease more than 20 years after infection, the overall rate of HCV-related liver disease was relatively low in our study. The benign course of our study could be explained by the mode of contamination and the age of the patients at contamination (mean age: $28.2 \pm 7.2$ years). Patients infected at a young age are at lower risk for progressive liver disease. ${ }^{8}$ The mode of HCV transmission offers a particularly useful insight into the prognosis. For example, in a German study of 1833 women infected with HCVcontaminated $\mathrm{RH}_{0}$ (D) immunoglobulin, none of these women were found to have chronic active hepatitis or cirrhosis 15 years later. After 25 years' follow up, cirrhosis was found in only $0.5 \%$ of cases. ${ }^{5}$ This result is similar to another study of an outbreak of $\mathrm{HCV}$ infection from contaminated anti-D immunoglobulin. ${ }^{7}$ In other modes of contamination, such as blood transfusions, there is great variability in the long-term outcome of HCV infection. A group from Australia reviewed existing, published data, and based on an analysis of 57 studies, concluded that after about 20 years, cirrhosis had developed in $24 \%(11-37 \%)$ of people infected through blood transfusions, $22 \%(18-26 \%)$ who were evaluated at a tertiary care liver clinic, $7 \%(4-10 \%)$ of community-based cohort studies, and in $4 \%(1-7 \%)$ of blood donors. ${ }^{21}$

During our investigation, the infection was spontaneously resolved in some cases. The rate of spontaneous resolution in the present study was $20.32 \%$; $13.69 \%$ in the male group and $25.59 \%$ in the female group. The mean level of ALT, AST, and $\gamma$ - GT in HCV-RNA-positive cases was significantly higher than that in negative cases. Regarding sex, there is evidence that the rate of liver disease progression is lower in women than in men. ${ }^{22}$ Our study indicated that the viral spontaneous clearing was higher in women than in men. The cases who progressed to liver cirrhosis in our study were mostly males. The rate of ALT and/or AST abnormalities in males was significantly higher than that in females, indicating that males might be more prone to serious liver disease than females.

The role of alcohol consumption has been established as a daily intake greater than 40 or $50 \mathrm{~g}$ per day. ${ }^{23,24}$ In the present study, there was no correlation between the viral spontaneous clearance with alcohol consumption; however, liver cirrhosis incidence was related to an alcohol intake of more than $40 \mathrm{~g}$ every day. Although alcohol abuse has been clearly shown to increase the severity of hepatitis $\mathrm{C}$, with more rapid progression to cirrhosis and HCC, these effects relate mainly to patients with quite high daily alcohol intake. ${ }^{25,26}$ Much less is known on whether a light or moderate amount of alcohol might also exert a negative influence on $\mathrm{HCV}^{27}$ Alcohol consumption is difficult to quantify, and conclusions must be prudent. However, it seems that the influence of alcohol is independent of other factors, weaker than the influence of age, and is exerted only at toxic levels of intake.

As described previously, ${ }^{28,29}$ age appears to be an important determinant of progression. The data suggest that the younger the age at infection, the lower the rate of progression. In the present study, no difference was found in the rate of viral resolution in the different age groups, which is consistent with a previous report. ${ }^{30}$ In our study cohort, the age at infection for most donors might possibly have been relatively younger.

Transient elastography is painless, rapid ( $<5 \mathrm{~min})$, and easy to perform at the bedside or at the outpatient clinic. Importantly, the results are immediately available and independent from the opera- tor. In the $\mathrm{HCV}$ spontaneous clearance group, the liver stiffness was $5.30 \pm 1.72 \mathrm{kPa}$, and in the HCV chronic infection group, the liver stiffness was $11.32 \pm 9.76 \mathrm{kPa}$. There were correlations between ALT, AST, and PLT levels with liver stiffness: 30 donors $(16.95 \%)$ had liver stiffness $>12.5 \mathrm{kPa}$. Severe hepatic inflammation can affect the liver stiffness findings, and thus, care is required when assessing fibrosis stage using liver stiffness measurements in patients with severe inflammation. ${ }^{31}$

In the present study, 10 donors were serum anti-HCV S/CO $<5$. Our finding is similar to some previous studies, in that seroclearance of anti-HCV might be observed in immunocompetent HCVinfected individuals after a self-resolved infection. ${ }^{32,33}$ Prevalence studies are most often based on serological testing. Therefore, further studies should take into account the occurrence of seroclearance of anti-HCV after a past and self-resolved infection.

The silent onset of the acute phase of hepatitis $\mathrm{C}$ infection, coupled with the frequent lack of symptoms during the early stages of chronic infection, has meant that the natural history of hepatitis $\mathrm{C}$ virus infection has been very difficult to assess. The optimal study to assess progression is one in which the onset of infection is precisely defined; the infection emanates from a single, identified source; the case ascertainment is high; the study population is large; and where follow up is prospective, comprehensive, and of long duration. ${ }^{34}$ Such an idealized combination of study parameters is very difficult to achieve.

Five patients had co-infection with HBV when re-evaluated in 2008 using the Abbott kit, but none of these patients were HBV infected at the start of follow up. During follow up, none of the donors donated plasma, perhaps because the sensitivity of the Abbott kit is higher than the reagent used in 1991 or 1998.

Our retrospective, progressive study offered the possibility of investigating the long-term outcome of plasma donors with HCV infection. Unfortunately, the serological testing for anti-HCV was not available before 1990 in China; also, the samples were not to be collected during outbreaks between 1972 and 1990 in these donors for anti-HCV and HCV-RNA testing. Thus, it was impossible to define the accurate time of the onset of infection. The time of the onset of acute hepatitis non-A, non-B is known by the first time of ALT elevation. In donors with normal ALT levels, the lattermost plasma donation time was considered as onset of infection. When serological testing became available, all infected donors in our study tested positive for anti-HCV in 1991 or 1998. The results of our follow up, obtained in this large cohort of patients with predominantly chronic hepatitis $C$ virus genotype $1 \mathrm{~b}$ infection, showed a slowly-progressive liver disease.

In conclusion, this area has a high rate of chronicity in $\mathrm{HCV}$ infection due to plasma donation. Our study supports earlier data that although there is no significant mortality in the first 20 years after infection, later follow up shows that both morbidity and mortality increase. These data underline the progressive nature of chronic HCV infection due to plasma donation, and the need to identify and treat infected patients.

\section{Acknowledgment}

This work was supported by the National S\&T Major Project for Infectious Diseases Control (no. 2008ZX10002-013 and no. 2008ZX10002-012), Major State Basic Research Development Program of China (no. 2005CB522902 and no. 2007CB512900), 
National High-Tech R\&D Program of China (no. 2006AA02A410), and the National Natural Science Foundation of China (no 30800508).

\section{References}

1 Ascione A, Tartaglione T, Giuseppe Di Costanzo G. Natural history of chronic hepatitis C virus infection. Dig. Liver Dis. 2007; 39 (Suppl. 1): S4-7.

2 Sweeting MJ, De Angelis D, Brant LJ, Harris HE, Mann AG, Ramsay ME. The burden of hepatitis C in England. J. Viral Hepat. 2007; 14: 570-6.

3 Global Burden of Hepatitis C Working Group. Global burden of disease for hepatitis C. J. Clin. Pharmacol. 2004; 44: 20-9.

4 Seeff LB. Natural history of hepatitis C. Am. J. Med. 1999; 107: S10-15.

5 Wiese M, Grungreiff K, Guthoff W, Lafrenz M, Oesen U, Porst H. Outcome in a hepatitis $\mathrm{C}$ (genotype $1 \mathrm{~b}$ ) single source outbreak in Germany a 25-year multicenter study. J. Hepatol. 2005; 43: 590-8.

6 Seeff LB, Buskell-Bales Z, Wright EC et al. Long-term mortality after transfusion-associated non-A, non-B hepatitis. The National Heart, Lung, and Blood Institute Study Group. N. Engl. J. Med. 1992; 327: 1906-11.

7 Kenny-Walsh E. Clinical outcomes after hepatitis C infection from contaminated anti-D immune globulin. Irish Hepatology Research Group. N. Engl. J. Med. 1999; 340: 1228-33.

8 Vogt M, Lang T, Frosner G et al. Prevalence and clinical outcome of hepatitis $\mathrm{C}$ infection in children who underwent cardiac surgery before the implementation of blood-donor screening. N. Engl. J. Med. 1999; 341: 866-70.

9 Thomas DL, Astemborski J, Rai RM et al. The natural history of hepatitis $\mathrm{C}$ virus infection: host, viral, and environmental factors. JAMA 2000; 284: 450-6.

10 Ferenci P, Ferenci S, Datz C, Rezman I, Oberaigner W, Strauss R. Morbidity and mortality in paid Austrian plasma donors infected with hepatitis C at plasma donation in the 1970s. J. Hepatol. 2007; 47: 31-6.

11 Du SC, Tao QM, Zhu L. Typing on 5'-terminal noncoding region of hepatitis $\mathrm{C}$ virus genome with restrict endonuclease. Zhonghua Yixue Zazhi 1993; 73: 7-9.

12 Lin DY, Sheen IS, Chiu CT, Lin SM, Kuo YC, Liaw YF. Ultrasonographic changes of early liver cirrhosis in chronic hepatitis B: a longitudinal study. J. Clin. Ultrasound 1993; 21: 303-8.

13 Castéra L, Vergniol J, Foucher J et al. Prospective comparison of transient elastography, Fibrotest, APRI, and liver biopsy for the assessment of fibrosis in chronic hepatitis C. Gastroenterology 2005; 128: $343-50$.

14 Ghany MG, Strader DB, Thomas DL, Seeff LB, American Association for the Study of Liver Diseases. Diagnosis, management, and treatment of hepatitis C: an update. Hepatology 2009; 49: 1335-74.

15 Bruix J, Sherman M, Practice Guidelines Committee, American Association for the Study of Liver Diseases. Management of hepatocellular carcinoma. Hepatology 2005; 42: 1208-36.

16 Chitturi S, Farrell GC, Hashimoto E et al. Non-alcoholic fatty liver disease in the Asia-Pacific region: definitions and overview of proposed guidelines. J. Gastroenterol. Hepatol. 2007; 22: 778-87.

17 Dai ZC, Qi GM. The Viral Hepatitis of China: the Epidemiological of Serous. Beijing: Beijing Scientific and Technical Literature Publishers, 1997.

18 Center for Public Health Surveillance and Information Service, Center for Disease Control and Prevention of China. National data of class a, b and c communicable diseases. Disease Surveillance 2000-2010, 2011

19 Yokosuka O, Kojima H, Imazeki F et al. Spontaneous negativation of serum hepatitis $\mathrm{C}$ virus RNA is a rare event in type $\mathrm{C}$ chronic liver diseases: analysis of HCV RNA in 320 patients who were followed for more than 3 years. J. Hepatol. 1999; 31: 394-9.

20 Mazzeo C, Azzaroli F, Giovanelli S et al. Ten year incidence of $\mathrm{HCV}$ infection in northern Italy and frequency of spontaneous viral clearance. Gut 2003; 52: 1030-4.

21 Freeman AJ, Dore GJ, Low MG et al. Estimating progression to cirrhosis in chronic hepatitis C virus infection. Hepatology 2001; 34: 809-16.

22 Deuffic-Burban S, Poynard T, Valleron AJ. Quantification of fibrosis progression in patients with chronic hepatitis $\mathrm{C}$ using a Markov model. J. Viral Hepat. 2002; 9: 114-22.

23 Wiley TE, McCarthy M, Breidi L, McCarthy M, Layden TJ. Impact of alcohol on the histological and clinical progression of hepatitis $\mathrm{C}$ infection. Hepatology 1998; 28: 80-9.

24 Poynard T, Ratziu V, Charlotte F, Goodman Z, McHutchison J, Albrecht J. Rates and risk factors of liver fibrosis progression in patients with chronic hepatitis C. J. Hepatol. 2001; 34: 730-9.

25 Harris HE, Ramsay ME, Andrews N, Eldridge KP. Clinical course of hepatitis $\mathrm{C}$ virus during the first decade of infection: cohort study. BMJ 2002; 324: 450-3.

26 Szabo G, Aloman C, Polyak SJ, Weinman SA, Wands J, Zakhari S. Hepatitis C infection and alcohol use: a dangerous mix for the liver and antiviral immunity. Alcohol. Clin. Exp. Res. 2006; 30: 709-19.

27 Peters MG, Terrault NA. Alcohol use and hepatitis C. Hepatology 2002; 36: S220-5.

28 Minola E, Prati D, Suter F et al. Age at infection affects the longterm outcome of transfusion-associated chronic hepatitis $\mathrm{C}$. Blood 2002; 99: 4588-91.

29 Bellentani S, Tiribelli C. The spectrum of liver disease in the general population: lesson from the Dionysos study. J. Hepatol. 2001; 35 : 531-7.

30 Wei L, Wang QX, Xu XY et al. 12-25-year follow-up of hepatitis C virus infection in a rural area of Hebei province, China. Beijing Daxue Xuebao 2002; 34: 574-8.

31 Seo YS, Um SH, Suh SJ et al. Changes in liver stiffness during the course of acute hepatitis A. Korean J. Hepatol. 2008; 14: 465-73.

32 Takaki A, Wiese M, Maertens G et al. Cellular immune responses persist and humoral responses decrease two decades after recovery from a single-source outbreak of hepatitis C. Nat. Med. 2000; 6: 578-82.

33 Seeff LB, Hollinger FB, Alter HJ et al. Long-term mortality and morbidity of transfusion-associated non-A, non-B and type $C$ hepatitis: a National Heart, Lung, and Blood Institute collaborative study. Hepatology 2001; 33: 455-6.

34 Alter HJ. HCV natural history: the retrospective and prospective in perspective. J. Hepatol. 2005; 43: 550-2. 